\title{
1 Indirect effects of parental conflict on conspecific offspring development
}

2 J.M. Coughlan ${ }^{1,2}$

3 1. University of North Carolina at Chapel Hill, Biology Department

4 2. Yale University, EEB Department

5 Email: jcoug@email.unc.edu

6

7 Key Words: Endosperm, Hybridization, Hybrid Seed Inviability, Resource Competition,

8 Reproductive Isolation, Secondary Contact

9

10 Running head: Hybridization influences intraspecific seed development

11

12 Total Words of Main Text: 2895

13

14 Number of Figures: 2

15

16 Author Contributions: JMC conceived of this project, performed all experiments, analyzed the

17 data and wrote the paper.

18

19

20

21

22

23

24

25

26 


\section{$27 \quad$ Abstract}

28 Hybrid Seed Inviability (HSI) is a common barrier in angiosperms. Recent work suggests that

29 the rapid evolution of HSI may, in part, be due to conflict between maternal and paternal optima

30 for resource allocation to developing offspring (i.e. parental conflict). However, parental conflict

31 requires that paternally-derived resource acquiring alleles impose a maternal cost. I test this

32 requirement using three closely related species in the Mimulus guttatus species complex that

33 exhibit significant $\mathrm{HSI}$ and differ in their inferred histories of parental conflict. I show that the

34 presence of hybrid seeds significantly affects conspecific seed size for almost all crosses, such

35 that conspecific seeds are smaller after developing with hybrids from fathers with a stronger

36 history of conflict, and larger after developing with hybrids from fathers with a weaker history of

37 conflict. This work demonstrates a cost of paternally-derived alleles, and also has implications

38 for species fitness in secondary contact. 


\section{Introduction}

A fundamental source of conflict in viviparous organisms stems from differences between maternal and paternal optima for how many resources to allocate to developing offspring (i.e. parental conflict (Trivers 1974; Charnov 1979; Haig and Westoby 1989)). This is because in non-monogamous systems while maternity is guaranteed, fathers are not equally related to all offspring produced within a brood, and thus selection can favor the evolution of paternally-derived, resource acquiring alleles that come at a cost to either mothers directly or

60 indirectly by influencing other developing offspring in that brood (e.g. 'greedy alleles'; (Trivers

61 1974; Charnov 1979; Haig and Westoby 1989; Haig 1997; Wilkins and Haig 2001; Brandvain

62 2010)). Consequently, selection will then favor maternally-derived, resource repressive alleles,

63 and a co-evolutionary arms race may subsequently evolve (Trivers 1974; Charnov 1979; Haig

64 and Westoby 1989; Haig 1997; Wilkins and Haig 2001; Brandvain 2010). As such, parental conflict theory predicts that the severity of parental conflict is a reflection of the variance in paternity within broods (Queller 1984; Brandvain and Haig 2005; Brandvain et al. 2011; Willi

67 2013; Raunsgard et al. 2018). Parental conflict may be particularly important in systems where nutrients are partitioned directly, dynamically, and post-fertilization from maternal parents to developing offspring in utero via an intermediary tissue, such as placental or endosperm (Haig and Westoby 1989; Moore and Haig 1991; Zeh and Zeh 2000).

In seed plants, the endosperm is a nutritive tissue that is essential for proper embryo

72 development and is analogous to the placenta in mammals. Endosperm arises via the

73 fertilization of the central cell; a di-haploid structure within the megagametophyte, resulting in a

74 triploid tissue that is 2 maternal genomes: 1 paternal genome. The balance of $2 \mathrm{~m}: 1 \mathrm{p}$ in the

75 endosperm is crucial for its development, as many genes which are essential for proper

76 endosperm development are imprinted (i.e. genes are expressed based on whether they are

77 maternally or paternally derived), the balance of which allows development to proceed normally

78 (Scott et al. 1998; Köhler and Weinhofer-Molisch 2010). Much research using interploidy 
crosses has demonstrated that an overexpression of maternally expressed or paternally expressed genes results in canonical developmental defects across multiple plant systems and endosperm developmental programs (Scott et al. 1998; Kradolfer et al. 2013; Wolff et al. 2015; Lafon-Placette and Köhler 2016; Lafon-Placette et al. 2017; Morgan et al. 2021). Strikingly, excess of maternal or paternal expression results in growth-repressive or growth-excessive phenotypes, reminiscent of predictions of parental conflict. If these endosperm defects are severe enough they can cause embryo death, and as such seed inviability is thought to be a crucial reproductive barrier between plants of different ploidy levels (often referred to as 'Triploid Block'; (Comai 2005; Köhler et al. 2010, 2021; Sutherland and Galloway 2017; Morgan et al. 2021)). results from parent-of-origin specific growth defects in the endosperm (Brandvain and Haig 2005; Lowry et al. 2008; Briscoe Runquist et al. 2014; Rebernig et al. 2015; Garner et al. 2016; Lafon-Placette and Köhler 2016; Oneal et al. 2016; Lafon-Placette et al. 2017, 2018; Roth et al. 2018b, 2019; Coughlan et al. 2020b; Sandstedt et al. 2020; Gustafsson et al. 2021; iltaş et al.

94 2021). These patterns, while strikingly similar to the defects exemplified in interploidy crosses

95 (Lafon-Placette and Köhler 2016; Lafon-Placette et al. 2017; Städler et al. 2021), cannot be explained by genome-wide imbalances of maternal:paternal gene expression in the endosperm,

97 and must involve the evolution of paternal-excessive and maternal-repressive alleles. The 98 observation that interspecific diploid crosses often mirror inter-ploidy crosses has sparked a 99 conceptual framework to categorize diploid taxa according to the extent of maternal-repression 100 and paternal-excess that they exhibit when crossed to other diploids, referred to as their 101 Endosperm Balance Number (EBN;(Johnston et al. 1980; Katsiotis et al. 1995; Carputo et al. 102 1999; Johnston and Hanneman 1999; Lafon-Placette and Köhler 2016; Lafon-Placette et al. 103 2018; Städler et al. 2021)), or genome strength (Brandvain and Haig 2018). Differences 
104

105

106

107

108

109

110

between taxa in EBNs are thought to reflect different histories of parental conflict (LafonPlacette et al. 2018; Raunsgard et al. 2018; Coughlan et al. 2020b; Städler et al. 2021).

Although its role in underlying $\mathrm{HSI}$ is garnering much current support (Lafon-Placette et al. 2018; Coughlan et al. 2020b; İltaş et al. 2021), parental conflict may also play a secondary role in speciation in the context of secondary contact. Hybridization between closely related species that vary in EBNs can not only result in the loss of gametes (i.e. reproductive interference), but when hybrids are formed in a brood that also contains conspecific offspring, differences in the competitive ability between hybrid and conspecific siblings borne through differences in paternally-derived resource acquiring alleles may affect conspecific size, and consequently offspring fitness. In seed plants, seed size is often a proxy for various fitness components (such as the probability of germination, seedling size, and the number of flowers produced (Stanton 1984; Krannitz et al. 1991; Simons and Johnston 2000; Gómez 2004)). Thus, competition for limited maternal resources between hybrid and intraspecific siblings may have substantial implications for intraspecific fitness in secondary contact zones.

Here I use a model organism for ecology, evolution, and genetics; the Mimulus guttatus species complex to address if conspecific seed size varies when seeds are grown only with other conspecific siblings versus hybrid siblings from sires with different EBNs. Previously, I have shown that $M$. guttatus and a closely related species, $M$. decorus, are reproductively isolated by HSI, and patterns of HSI support a role for parental conflict (Coughlan et al. 2020b). Namely, hybrid seeds exhibit parent-of-origin specific growth defects (maternal-repressive and paternal-excess phenotypes) that are associated with parent-of-origin specific endosperm defects (Coughlan et al. 2020b). Mimulus decorus comprises two distinct diploid lineages; one that exhibits substantially lower EBN than M. guttatus and one that exhibits a higher EBN than M. guttatus, despite a relatively recent divergence time (roughly 230kya; (Coughlan et al. $2020 b)$ ). Here, I leverage this diversity of EBNs in this group to assess indirect growth effects in conspecific seeds when these seeds are grown alongside hybrid siblings that vary in their 
father's EBN. This work is one of the first to provide an explicit test of the cost of paternally derived, resource acquiring alleles; a central prediction of parental conflict. Moreover, the results of this experiment have implications for secondary contact between species that differ in EBN.

\section{Materials \& Methods}

Plant materials and crosses

I grew between 6-16 replicate lines of a single genotype for each of M. guttatus (IM62),

137 Southern M. decorus (OD11), and Northern M. decorus (HWY15D). Previous work using

138 population genomics and experimental crosses suggests that Northern $M$. decorus produces

139 relatively weak dams and sires (i.e. has a low EBN), and is predicted to have experienced the

140 weakest history of parental conflict, while Southern M. decorus produces relatively strong dams

141 and sires (i.e. a high EBN), and is predicted to have experienced the strongest history of

142 parental conflict (Coughlan et al. 2020b). Mimulus guttatus exhibits an EBN intermediate to the

143 two genetic lineages of $M$. decorus (i.e. stronger than Northern $M$. decorus, but weaker than

144 Southern M. decorus; (Coughlan et al. 2020b)). I first cold and dark stratified seeds in water for

145 one week, then dispersed them on moist Fafard 4P soil (SunGro Horticultural Inc) in the

146 University of North Carolina at Chapel Hill greenhouses. I transferred early germinants to

147 individual 2 1/2" pots and grew plants in warm, long day conditions (16hours of light/ 20C). opened and well before natural pollen dehiscence. All species used in this experiment have a highly outcrossing morphology and very rarely (if ever) set autogamous selfed seed in the

151 greenhouse (Coughlan and Willis 2019; Coughlan et al. 2020b). In accordance with this 152 observation, no unpollinated stigma bore a fruit during the course of this experiment. For each 153 species, stigmas were pollinated with either pure self pollen or a mixture of self pollen and 154 pollen from another species. For both pollination types, anthers were manually dehisced on a 155 glass slide, then I manually transferred pollen to an open stigma using fine forceps. For the 
mixed pollination treatment, anthers were manually dehisced until a roughly equal quantity of pollen from each species was available, then pollen samples were thoroughly mixed with fine forceps. The exact ratio of pollen from each parent is unlikely to have been equal for every cross, and indeed fertilization rates between intra- and inter-specific fathers did significantly differ for may fruits, which may reflect departures from a 1:1 ratio of pollen genotypes or differences in competitive ability of pollen genotypes (see Table S2). Nonetheless, the aim of this work is to assess if the presence of hybrid siblings influences intraspecific seed size, and as such an exact 1:1 ratio of paternal genotypes in the pollen is unnecessary. I collected fully ripened fruits shortly before natural dehiscence. All fruits were dried at ambient temperatures for at least one week before seeds were counted, categorized, and measured. In total, an average of 26.5 fruits (range: $20-31$ fruits) were quantified for each species and cross type combination

167 (see Figure 1 for overview of experimental design).

Seed Quantification

For each cross, all fertilized seeds were counted and quantified for viability based on morphology, with shriveled, disc-like, or concave seeds scored as inviable. Morphology has previously been shown to be a good indicator of viability in Mimulus (Garner et al. 2016;

173 Coughlan et al. 2020b). In four of the six mixed pollen treatments, hybrids are almost always 174 inviable $(<<<0.1 \%$ viability. In contrast, selfed crosses show generally low rates of inviability 175 ( 95\% viable); (Coughlan et al. 2020b)). We therefore assumed that any viable seed in these 176 four mixed pollination crosses were likely to be a product of self fertilization. In two of the six 177 mixed-pollen crosses, hybrid seeds are generally viable, though noticeably smaller and produce 178 much darker seed coats than selfed seed ( $M$. guttatus mothers x Northern $M$. decorus pollen 179 donors and Southern M. decorus mothers x M. guttatus pollen donors). In the case of Southern $180 M$. decorus, crosses in which pollen was mixed with $M$. guttatus yielded a generally high level of 181 fruit failure, and thus this cross type was excluded from subsequent analysis. In the case of 
crosses involving $M$. guttatus mothers with a mixture of $M$. guttatus and Northern $M$. decorus pollen, a subset of putative self-fertilized and putative hybrid seeds were grown to confirm that designations based on seed phenotype accurately indicated paternal genotype. All seeds which were presumed to be self fertilized were indeed conspecific seeds, and only 2/86 presumed hybrids were likely conspecific seeds ( $2.3 \%$ error rate; Figure S1). I then measured the area of all viable, putatively non-hybrid seeds using ImageJ (Schneider et al. 2012) for the remaining 8 cross type/maternal parent combinations. In total, this resulted in an average of 29,55 , and 128 seeds measured per fruit, for crosses involving Southern M. decorus, M. guttatus, and Northern M. decorus as the maternal donor, respectively. In total, I measured 16,199 seeds across 215 fruits for all 8 experimental cross types.

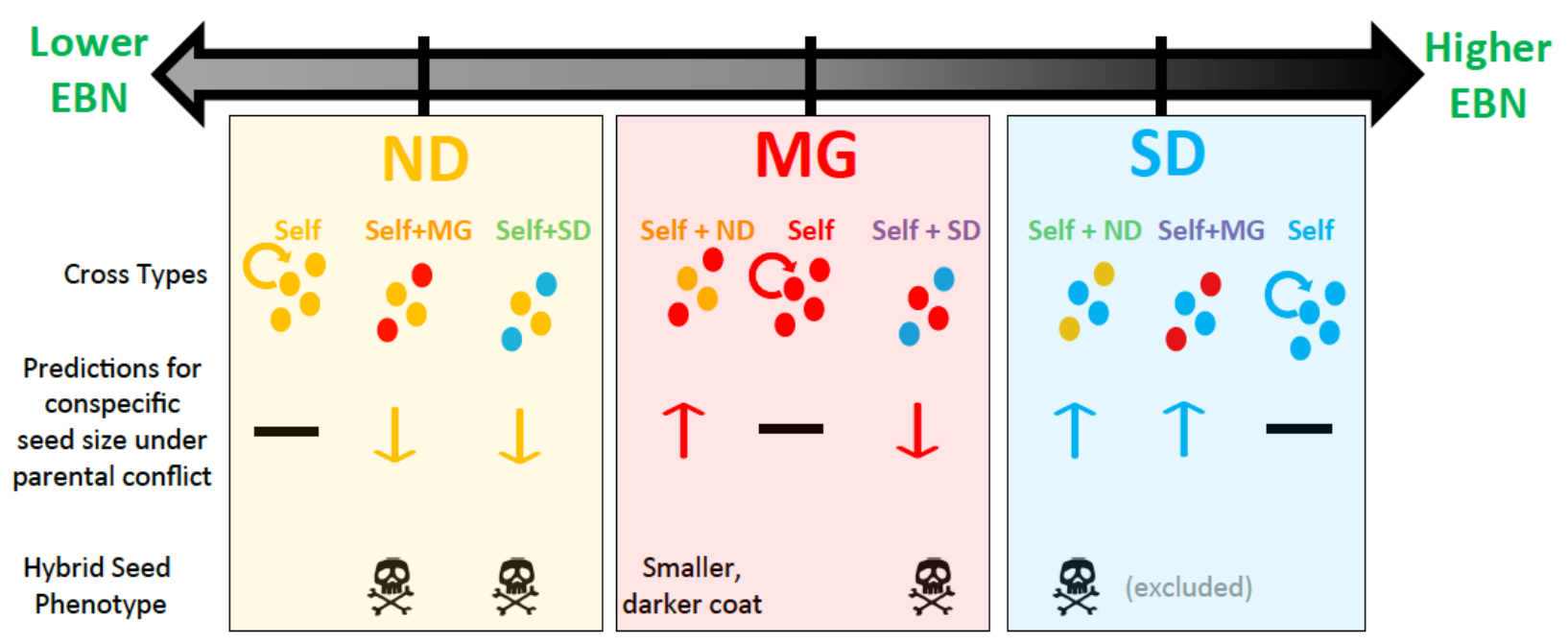

Figure 1: Overview of the experimental design. This experiment leveraged natural variation in $\mathrm{EBN}$ across three species $(\mathrm{ND}=$ Northern $M$. decorus, $\mathrm{MG}=$ M. guttatus, $\mathrm{SD}=$ Southern $M$. decorus; outlined in (Coughlan et al. 2020b)). To compare conspecific seed size when conspecific seeds developed along full siblings versus half siblings whose sires vary in EBN, nine types of crosses were completed: each species was self fertilized, or fertilized with a mixture of self-pollen and pollen from another species. After excluding putative hybrid seeds based on diagnostic phenotypes (hybrids having inviable or much smaller and darker seeds; see Figure S1 for confirmation), all conspecific seeds for each cross type were measured for total area. Prediction based on parental conflict theory are outlined: conspecific seeds developing with hybrid siblings sired by a higher EBN father should be smaller (exemplified by both mixed crosses involving Northern $M$. decorus as the dam), while conspecific seeds 
204 developing alongside hybrid siblings sired by a lower EBN father should be larger (exemplified by both mixed crosses involving Southern $M$. decorus as the dam).

Analyses

To assess if the presence of hybrid siblings affected the size of intraspecific seeds, I used a linear mixed model with log(seed area) as the response variable and cross type (e.g. pure selffertilized, mixed pollen with species 1 and mixed pollen with species 2 as the levels), and the total number of seeds per fruit as fixed effects. As the same plant was used for multiple crosses, and multiple seeds were measured from a single fruit, I also included maternal replicate and fruit replicate as random effects. The significance of the fixed effects were assessed by a Type III

214 Wald $\chi^{2}$ test using the Ime4 and car packages in R (Bates et al. 2012; Fox and Weisberg 2018).

215 Significance between cross types were assessed using the emmeans package in R (Russell 216 2019). These analyses were performed for each maternal genotype separately.

\section{$\underline{\text { Results }}$}

219 The presence of hybrid seeds affects intraspecific seed size

The presence of hybrid seeds significantly affected conspecific seed size in almost all crosses (Figure 2, Table S1). The direction of these effects depended on the type of hybrids that conspecific seeds developed alongside (Figure 2). For M. guttatus, conspecific seeds were smaller when they developed along hybrids sired by a higher EBN pollen donor (i.e. Southern M. decorus), and larger when they developed alongside hybrid siblings sired by a lower EBN pollen donor (i.e. Northern M. decorus; Figure 2). Similarly, for Southern M. decorus, conspecific seeds were larger when they developed alongside hybrid siblings sired by a lower EBN pollen

227 donor (i.e. Northern M. decorus; Figure 2). For Northern M. decorus, conspecific seeds were 228 significantly smaller when developing alongside hybrid siblings sired by the highest EBN pollen 
difference in intraspecific seed size between fruits containing only pure intraspecific selfs and

231 fruits containing both intraspecific selfs and hybrid siblings sired by M. guttatus (which has a

232 higher EBN than Northern M. decorus, but a lower EBN that Southern M. decorus). Overall,

233 these effects are relatively small, for example intraspecific $M$. guttatus seeds are $\sim 5 \%$ larger

234 when developing alongside hybrids from a lower EBN father and $\sim 7 \%$ smaller when developing

235 alongside hybrids from a higher EBN father (see Figure 2 for all estimated effect sizes based on

236 estimated marginal means).
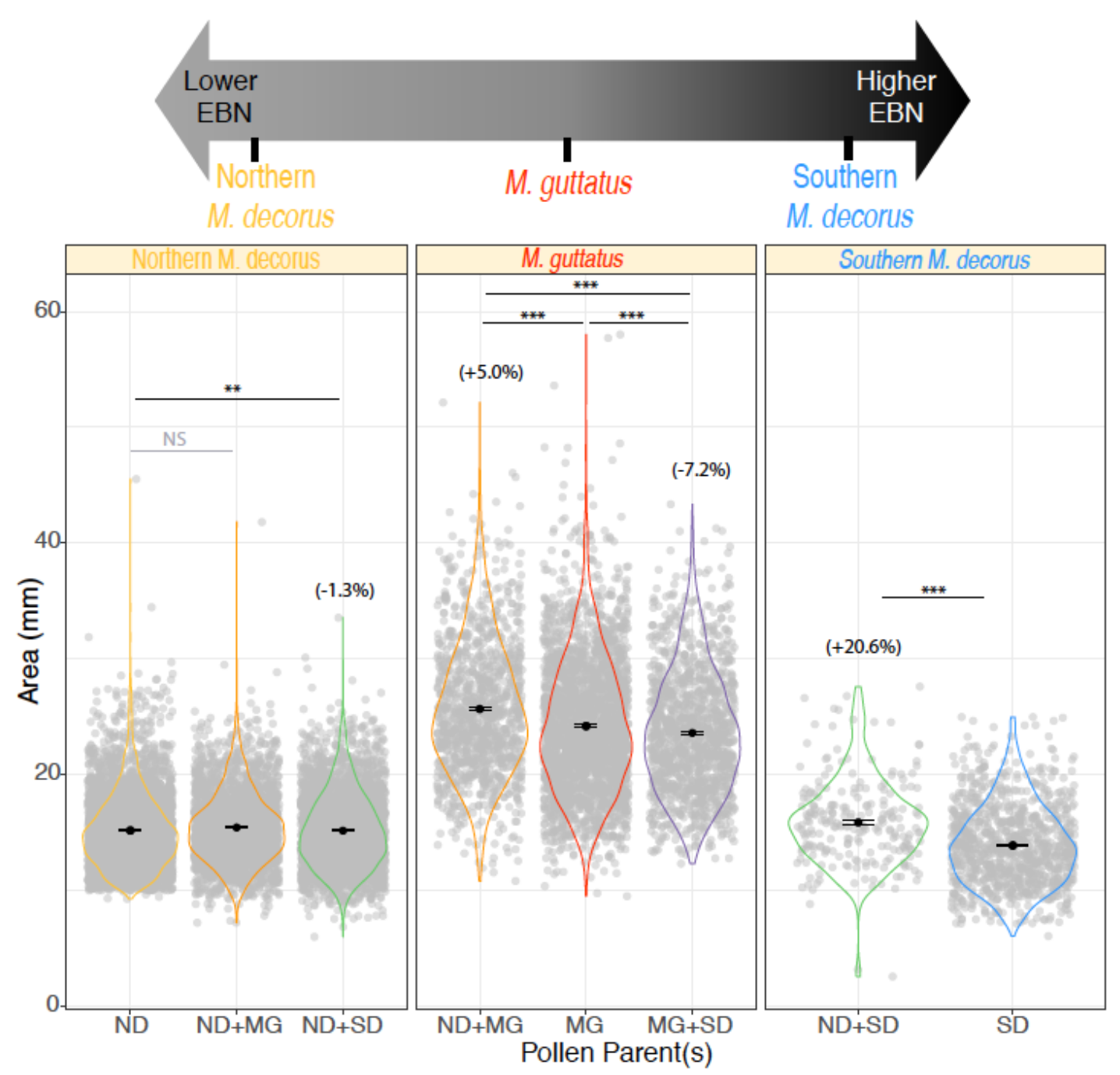

Figure 2: Intraspecific seed size differs between developmental contexts. For each 
(in $\mathrm{mm}$ ). Each panel depicts seeds produced from each genotype as the maternal parent, while colors of the violins indicate the pollen donor(s) (note: while only conspecific seeds were measured, for mixed pollination crosses I use an intermediate color between the two pollen donors for contrast to pure conspecific crosses). Filled, solid black points represent the means and standard errors, while translucent, grey points are all raw data. For crosses that show a significant difference in conspecific seed size, the effect size relative to conspecific seeds that developed alongside full siblings as estimated from the emmeans package in $R$ (Russell 2019) are shown in brackets. Significant differences were determined using a linear mixed effect model (See Table S1 for output). Note that for Southern $M$. decorus fruits generally failed when fertilized with a combination of self-pollen and pollen from $M$. guttatus, so this cross was excluded from further analysis.

\section{Discussion}

Here I show that conspecific seed size is influenced by the presence of hybrid siblings during development. These results are consistent with the idea that paternally-derived, resource acquiring alleles are costly to less resource-competitive siblings developing in the same brood (and in turn, to maternal parents). Although these maternal costs are a central prediction of parental conflict theory, very few studies have empirically demonstrated them. To my knowledge, the only other study to show these costs utilized variation between maize accessions for paternally-derived resource acquiring alleles to show that seed size differed when half-siblings whose fathers differed in their competitive ability developed alongside one another relative to when the same genotypes developed alongside full siblings (Cailleau et al. 2018). Here, I leverage proposed differences in EBN between recently diverged taxa to illustrate a similar phenomenon.

While a growing body of evidence has highlighted the role of parental conflict in the origins of reproductive isolation (namely $\mathrm{HSI}$, and early-onset hybrid inviability in mammalian systems; (Vrana et al. 1998, 2000; Brekke and Good 2014; Brekke et al. 2016, 2021; Oneal et al. 2016; Lafon-Placette et al. 2018; Roth et al. 2018a; Coughlan et al. 2020b; Sandstedt et al. 2020; Arévalo et al. 2021)), the work presented here highlights a secondary role of parental conflict in speciation: hybridization between species that vary in their histories of parental conflict may result in indirect effects to intraspecific offspring development, in the event that 
273 intraspecific offspring develop alongside hybrids. In this system, M. guttatus co-occurs with both

274 Northern and Southern M. decorus for large portions of their range (JMC personal obs;

275 (Coughlan et al. 2020a)), and are thought to routinely hybridize and introgress (JMC

276 unpublished data; (Puzey et al. 2017)). Although seed size differences have been shown to

277 influence several components of fitness in other systems (germination probability, seedling

278 survivorship, flower production; (Stanton 1984; Simons and Johnston 2000; Gómez 2004)),

279 these effects are likely to be context specific (for example, based on the competitive

280 environment; (Stanton 1984)), and substantial fieldwork and further experimentation is required

281 to quantify fitness effects in this system. However, one intriguing finding of this work is that the

282 consequences of hybridization for intraspecific seed development are not always costs. If

283 hybridization with fathers with lower EBNs consistently results in slightly larger conspecific

284 seeds, this hybridization might actually result in a fitness benefit to individual seeds. However,

285 this potential benefit is likely a very small one, and moreover hybridization likely still results in an

286 overall cost to maternal parents and a loss of inclusive fitness to individual seeds, given the loss

287 of gametes to inviable hybrid offspring. Depending on the rates of hybridization and the

288 competitive environment in which seeds (or in the case of mammals, young offspring) find

289 themselves, this work may have significant implications for the dynamics of hybridization and

290 coexistence of species that vary in their histories of conflict and find themselves in secondary

291 contact.

292

293 Data Availability

294 All raw data are available under the Dryad submission https://doi.org/10.5061/dryad.m905qfv2d.

295 Summaries of all crosses are included in Supplementary Table 2 of this manuscript.

296

297 Acknowledgements 
Thanks to the Willis, Sweigart, Sobel, Franks and Matute labs for providing helpful feedback on

this manuscript. I would also like to graciously thank Polly Campbell and Sarah Gardner for a

particularly creative seminar question that greatly inspired my thought process in designing this

experiment. JMC was supported by an NSF DEB Dimensions of Biodiversity grant

awarded to Daniel Matute (DEB-DOB-1737752).

\section{References}

Arévalo, L., S. Gardner, and P. Campbell. 2021. Haldane's rule in the placenta: Sex- biased misregulation of the Kcnq1 imprinting cluster in hybrid mice. Evolution 75:86-100. Bates, D., M. Maechler, B. Bolker, S. Walker, R. H. B. Christensen, H. Singmann, B. Dai, et al. 2012. Package "Ime4." CRAN. R Foundation for Statistical Computing, Vienna, Austria. Brandvain, Y. 2010. Matrisibs, Patrisibs, and the Evolution of Imprinting on Autosomes and Sex Chromosomes. The American naturalist 176:511-521.

Brandvain, Y., and D. Haig. 2005. Divergent mating systems and parental conflict as a barrier to hybridization in flowering plants. The American naturalist 166:330-338.

_ 2018. Outbreeders pull harder in a parental tug-of-war. Proceedings of the National Academy of Sciences of the United States of America 115:11354-11356.

Brandvain, Y., J. Van Cleve, F. Ubeda, and J. F. Wilkins. 2011. Demography, kinship, and the evolving theory of genomic imprinting. Trends in genetics: TIG 27:251-257.

Brekke, T. D., and J. M. Good. 2014. Parent-of-origin growth effects and the evolution of hybrid inviability in dwarf hamsters. Evolution; international journal of organic evolution 68:3134-3148. Brekke, T. D., L. A. Henry, and J. M. Good. 2016. Genomic imprinting, disrupted placental expression, and speciation. Evolution; international journal of organic evolution 70:2690-2703. Brekke, T. D., E. C. Moore, S. C. Campbell-Staton, C. M. Callahan, Z. A. Cheviron, and J. M. Good. 2021. X chromosome-dependent disruption of placental regulatory networks in hybrid dwarf hamsters. Genetics 218.

Briscoe Runquist, R. D., E. Chu, J. L. Iverson, J. C. Kopp, and D. A. Moeller. 2014. Rapid evolution of reproductive isolation between incipient outcrossing and selfing Clarkia species. Evolution; international journal of organic evolution 68:2885-2900.

Cailleau, A., D. Grimanelli, E. Blanchet, P. O. Cheptou, and T. Lenormand. 2018. Dividing a maternal pie among half-sibs: Genetic conflicts and the control of resource allocation to seeds in maize. The American naturalist 192:577-592.

Carputo, D., L. Monti, J. E. Werner, and L. Frusciante. 1999. Uses and usefulness of endosperm balance number. TAG. Theoretical and applied genetics. Theoretische und angewandte Genetik 98:478-484.

Charnov, E. L. 1979. Simultaneous hermaphroditism and sexual selection. Proceedings of the National Academy of Sciences of the United States of America 76:2480-2484.

Comai, L. 2005. The advantages and disadvantages of being polyploid. Nature reviews. Genetics 6:836-846.

Coughlan, J. M., M. W. Brown, and J. H. Willis. 2020a. The genetic architecture and evolution of life history divergence among perennials in the Mimulus guttatus species complex. Proceedings of the Royal Society B: Biological Sciences 288. 
Coughlan, J. M., and J. H. Willis. 2019. Dissecting the role of a large chromosomal inversion in life history divergence throughout the Mimulus guttatus species complex. Molecular ecology 28:1343-1357.

Coughlan, J. M., M. Wilson Brown, and J. H. Willis. 2020b. Patterns of Hybrid Seed Inviability in the Mimulus guttatus sp. Complex Reveal a Potential Role of Parental Conflict in Reproductive Isolation. Current biology 30:83-93.e5.

Fox, J., and S. Weisberg. 2018. An R Companion to Applied Regression. SAGE Publications. Garner, A. G., A. M. Kenney, L. Fishman, and A. L. Sweigart. 2016. Genetic loci with parentof- origin effects cause hybrid seed lethality in crosses between Mimulus species. The New phytologist 211:319-331.

Gómez, J. M. 2004. Bigger is not always better: conflicting selective pressures on seed size in Quercus ilex. Evolution 58:71-80.

Gustafsson, A. L. S., G. Gussarova, L. Borgen, H. Ikeda, A. Antonelli, L. Marie-Orleach, L. H. Rieseberg, et al. 2021. Rapid Evolution of Postzygotic Reproductive Isolation is Widespread in Arctic Plant Lineages. Annals of Botany mcab128.

Haig, D. 1997. Parental antagonism, relatedness asymmetries, and genomic imprinting. Proceedings of the Royal Society B: Biological Sciences 264:1657-1662.

Haig, D., and M. Westoby. 1989. Parent-specific gene expression and the triploid endosperm. The American naturalist 134:147-155. İltaş, Ö., M. Svitok, A. Cornille, R. Schmickl, and C. Lafon Placette. 2021. Early evolution of reproductive isolation: A case of weak inbreeder/strong outbreeder leads to an intraspecific hybridization barrier in Arabidopsis lyrata. Evolution 75:1466-1476.

Johnston, S. A., T. P. den Nijs, S. J. Peloquin, and R. E. Hanneman Jr. 1980. The significance of genic balance to endosperm development in interspecific crosses. TAG. Theoretical and applied genetics 57:5-9.

Johnston, S. A., and R. E. Hanneman. 1999. The nature of the genetic control of Endosperm Balance Number based on aneuploid analysis of Datura. Sexual plant reproduction 12:71-75. Katsiotis, A., R. E. Hanneman, and R. A. Forsberg. 1995. Endosperm Balance Number and the polar-nuclei activation hypotheses for endosperm development in interspecific crosses of Solanaceae and Gramineae, respectively. TAG. Theoretical and applied genetics 91:848-855. Köhler, C., K. Dziasek, and G. Del Toro-De León. 2021. Postzygotic reproductive isolation established in the endosperm: mechanisms, drivers and relevance. Philosophical transactions of the Royal Society of London. Series B, Biological sciences 376:20200118.

Köhler, C., O. Mittelsten Scheid, and A. Erilova. 2010. The impact of the triploid block on the origin and evolution of polyploid plants. Trends in genetics: TIG 26:142-148.

Köhler, C., and I. Weinhofer-Molisch. 2010. Mechanisms and evolution of genomic imprinting in plants. Heredity 105:57-63.

Kradolfer, D., P. Wolff, H. Jiang, A. Siretskiy, and C. Köhler. 2013. An imprinted gene underlies postzygotic reproductive isolation in Arabidopsis thaliana. Developmental cell 26:525-535.

Krannitz, P. G., L. W. Aarssen, and J. M. Dow. 1991. The effect of genetically based differences in seed size on seedling survival in Arabidopsis Thaliana (Brassicaceae). American Journal of Botany 78:446-450.

Lafon-Placette, C., M. R. Hatorangan, K. A. Steige, A. Cornille, M. Lascoux, T. Slotte, and C. Köhler. 2018. Paternally expressed imprinted genes associate with hybridization barriers in Capsella. Nature plants 4:352-357.

Lafon-Placette, C., I. M. Johannessen, K. S. Hornslien, M. F. Ali, K. N. Bjerkan, J. Bramsiepe, B. M. Glöckle, et al. 2017. Endosperm-based hybridization barriers explain the pattern of gene flow between Arabidopsis lyrata and Arabidopsis arenosa in Central Europe. Proceedings of the National Academy of Sciences of the United States of America 114:E1027-E1035. Lafon-Placette, C., and C. Köhler. 2016. Endosperm-based postzygotic hybridization barriers: 
390

391

392

393

394

395

396

397

398

399

400

401

402

403

404

405

406

407

408

409

410

411

412

413

414

415

416

417

418

developmental mechanisms and evolutionary drivers. Molecular ecology 25:2620-2629. Lowry, D. B., J. L. Modliszewski, K. M. Wright, C. A. Wu, and J. H. Willis. 2008. The strength and genetic basis of reproductive isolating barriers in flowering plants. Philosophical transactions of the Royal Society of London. Series B, Biological sciences 363:3009-3021. Moore, T., and D. Haig. 1991. Genomic imprinting in mammalian development: a parental tugof-war. Trends in genetics: TIG 7:45-49.

Morgan, E. J., M. Čertner, M. Lučanová, U. Deniz, K. Kubíková, A. Venon, O. Kovářík, et al. 2021. Disentangling the components of triploid block and its fitness consequences in natural diploid-tetraploid contact zones of Arabidopsis arenosa. New Phytologist 232: 1449-1462.

Oneal, E., J. H. Willis, and R. G. Franks. 2016. Disruption of endosperm development is a major cause of hybrid seed inviability between Mimulus guttatus and Mimulus nudatus. New Phytologist 210:1107-1120.

Puzey, J. R., J. H. Willis, and J. K. Kelly. 2017. Population structure and local selection yield high genomic variation in Mimulus guttatus. Molecular ecology 26:519-535.

Queller, D. C. 1984. Models of kin selection on seed provisioning. Heredity 53:151-165.

Raunsgard, A., Ø. H. Opedal, R. K. Ekrem, J. Wright, G. H. Bolstad, W. S. Armbruster, and C. Pélabon. 2018. Intersexual conflict over seed size is stronger in more outcrossed populations of a mixed-mating plant. Proceedings of the National Academy of Sciences of the United States of America 115:11561-11566.

Rebernig, C. A., C. Lafon-Placette, M. R. Hatorangan, T. Slotte, and C. Köhler. 2015. Nonreciprocal Interspecies Hybridization Barriers in the Capsella Genus Are Established in the Endosperm. PLoS genetics 11:e1005295.

Roth, M., A. M. Florez-Rueda, S. Griesser, M. Paris, and T. Städler. 2018a. Incidence and developmental timing of endosperm failure in post-zygotic isolation between wild tomato lineages. Annals of Botany 121:107-118.

Roth, M., A. M. Florez-Rueda, M. Paris, and T. Städler. 2018b. Wild tomato endosperm transcriptomes reveal common roles of genomic imprinting in both nuclear and cellular endosperm. The Plant journal: for cell and molecular biology 95:1084-1101.

Roth, M., A. M. Florez-Rueda, and T. Städler. 2019. Differences in effective ploidy drive genome-wide endosperm expression polarization and seed failure in wild tomato hybrids. Genetics 212:141-152.

Russell, L. 2019. emmeans: estimated marginal means, aka least-squares means. R package version 1.4. 2.

Sandstedt, G. D., C. A. Wu, and A. L. Sweigart. 2020. Evolution of multiple postzygotic barriers between species of the Mimulus tilingii complex. Evolution, 75: 600-613

Schneider, C. A., W. S. Rasband, and K. W. Eliceiri. 2012. NIH Image to ImageJ: 25 years of image analysis. Nature methods 9:671-675.

Scott, R. J., M. Spielman, J. Bailey, and H. G. Dickinson. 1998. Parent-of-origin effects on seed development in Arabidopsis thaliana. Development 125:3329-3341.

Simons, A. M., and M. O. Johnston. 2000. Variation in seed traits of Lobelia inflata (Campanulaceae): Sources and fitness consequences. American Journal of Botany 87:124132.

Städler, T., A. M. Florez-Rueda, and M. Roth. 2021. A revival of effective ploidy: the asymmetry of parental roles in endosperm-based hybridization barriers. Current opinion in plant biology 61:102015.

Stanton, M. L. 1984. Seed variation in wild radish: Effect of seed size on components of seedling and adult fitness. Ecology 65:1105-1112.

Sutherland, B. L., and L. F. Galloway. 2017. Postzygotic isolation varies by ploidy level within a polyploid complex. New Phytologist 213:404-412.

Trivers, R. L. 1974. Parent-offspring conflict. Integrative and comparative biology 14:249-264. 
Vrana, P. B., J. A. Fossella, P. Matteson, T. del Rio, M. J. O’Neill, and S. M. Tilghman. 2000. Genetic and epigenetic incompatibilities underlie hybrid dysgenesis in Peromyscus. Nature Vrana, P. B., X. J. Guan, R. S. Ingram, and S. M. Tilghman. 1998. Genomic imprinting is disrupted in interspecific Peromyscus hybrids. Nature genetics 20:362-365.

445 Wilkins, J. F., and D. Haig. 2001. Genomic imprinting of two antagonistic loci. Proceedings of the Royal Society B: Biological Sciences 268:1861-1867. Willi, Y. 2013. The battle of the sexes over seed size: support for both kinship genomic imprinting and interlocus contest evolution. American Naturalist 181:787-798. Wolff, P., H. Jiang, G. Wang, J. Santos-González, and C. Köhler. 2015. Paternally expressed imprinted genes establish postzygotic hybridization barriers in Arabidopsis thaliana. eLife 4:114. conflict hypothesis. BioEssays: news and reviews in molecular, cellular and developmental 
A

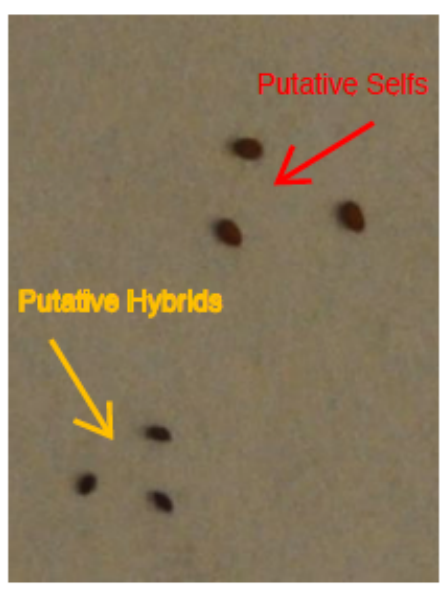

B

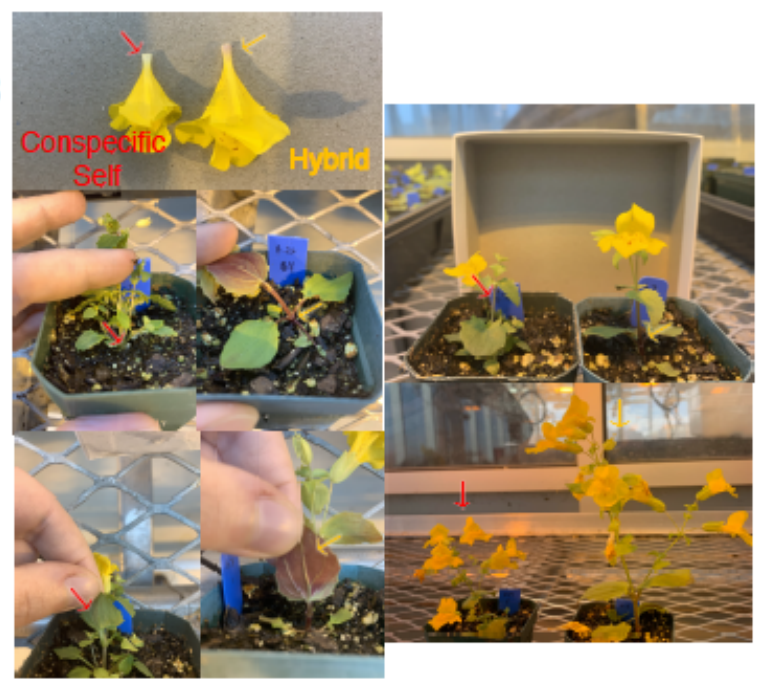

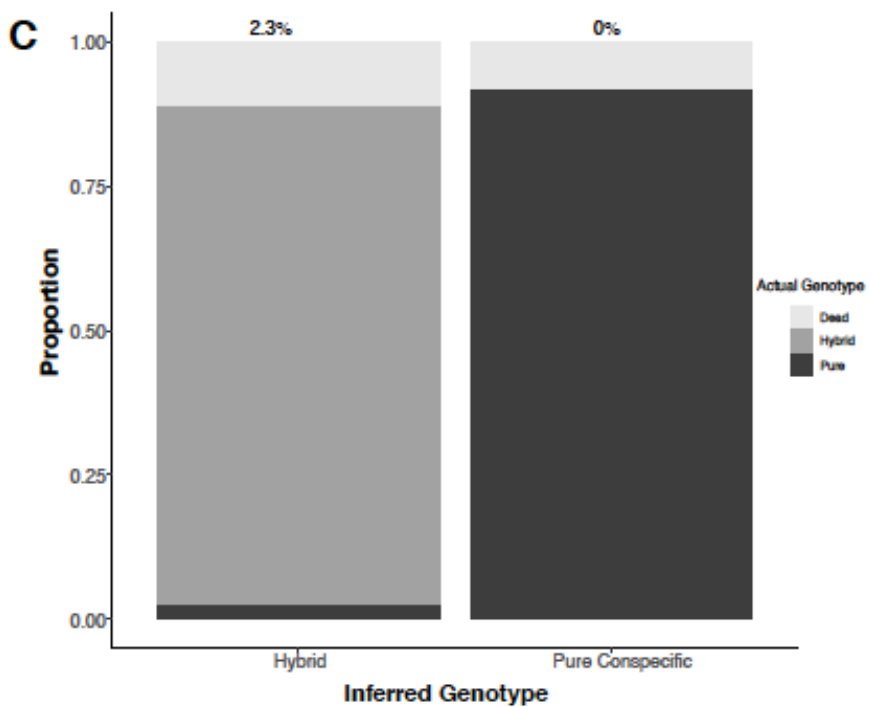

Inferred Genotype

Figure S1: Confirmation of paternal genotypes for mixed pollination crosses involving $\boldsymbol{M}$. guttatus as the dam and mixed pollen from $M$. guttatus and Northern M. decorus. (A) Putative hybrids and putative self-fertilized seeds exhibit distinct seed characteristics; hybrids are smaller and have much darker seed coats. To confirm paternal genotype, a subset of putative selfs and putative hybrids were grown. Plants differ in a number of diagnostic characters (selfs on the left, hybrids on the right), including: presence anthocyanin pigmentation in the base of the corolla in hybrids (top left), the presence of stolons in hybrids (middle left), the presence of anthocyanin pigmentation on the underside of the leaf in hybrids (bottom left), stems with anthocyanin pigmentation in hybrids (top right), and overall size; both of flowers and total plant, wherein hybrids are larger (bottom right). (C) Based on this set of characters, there were no hybrids that were designated as selfed seed and only $\sim 2 \%$ of seeds designated as hybrids were in fact conspecific seeds. 


\section{Supplemental Tables}

489 Table S1: LMER outputs for each species as maternal parent. In all cases, log(seed area) was

490 the response variable, with Cross Type (pure-self pollinated, mixed pollen with species 1, mixed

491 pollen with species 2 as the levels), and the total number of seeds per fruit as fixed effects.

492 Maternal plant replicate and fruit replicate were included as random effects. Significance of fixed

493 effects was determined using Type III Wald $\chi^{2}$ test using the Ime4 and car packages in $\mathrm{R}$

494 (Bates et al. 2012; Fox and Weisberg 2018).

\begin{tabular}{|c|c|c|c|}
\hline \multicolumn{4}{|c|}{ Norther M. decorus (Hwy15D) } \\
\hline Response & $\boldsymbol{F}$ & DF & $\mathbf{p}$ \\
\hline Intercept & 10620.635 & 1 & $<0.001^{* * *}$ \\
\hline Cross Type & 10.017 & 2 & $0.0067^{* *}$ \\
\hline $\begin{array}{l}\text { Total Num. of } \\
\text { seeds }\end{array}$ & 156.698 & 1 & $<0.001^{* * *}$ \\
\hline \multicolumn{4}{|c|}{ M. guttatus (IM62) } \\
\hline Intercept & 15122.371 & 1 & $<0.0001^{* * *}$ \\
\hline Cross Type & 124.602 & 2 & $<0.0001^{\star * *}$ \\
\hline $\begin{array}{l}\text { Total Num. of } \\
\text { seeds }\end{array}$ & 33.538 & 1 & $<0.0001^{* * *}$ \\
\hline \multicolumn{4}{|c|}{ Southern M. decorus (OD11) } \\
\hline Intercept & 3891.8363 & 1 & $<0.0001^{* * *}$ \\
\hline Cross Type & 88.9300 & 2 & $<0.0001^{* * *}$ \\
\hline $\begin{array}{l}\text { Total Num. of } \\
\text { seeds }\end{array}$ & 7.0686 & 1 & $0.0078^{* *}$ \\
\hline
\end{tabular}


Table S2: Number of seeds produced, proportion inviable, and average seed size per fruit for all

$$
\text { crosses. } \text { Mat }=\text { Maternal genotype; } \text { Mat. } \mathbf{R e p}=\text { individual replicate of that genotype; } \text { Pat= }
$$

Paternal donor(s); CR= Cross Replicate (fruit replicate for each Maternal/Paternal combination);

Viable $=$ Number of viable seeds; Inviable $=$ Number of inviable seeds; Total $=$ total number of

$$
\text { seeds produced per fruit; Prop= proportion of inviable seeds; } \mathbf{A A}=\text { average seed area }(\mathrm{mm}) \text {, }
$$

507 Sig= is there a significant deviation from 1:1 pollination of the two paternal genotypes (SIG=

508 significant deviation, NS= Not-significant, NA= not applicable (i.e. only one paternal donor))).

\begin{tabular}{|l|l|l|l|l|l|l|l|l|l|}
\hline Mat & Mat.Rep & Pat & CR & Viable & Inviable & Total & Prop & AA & Sig? \\
\hline IM62 & 4 & OD+IM & 1 & 20 & 8 & 28 & 0.2857 & 21.6246 & NS \\
\hline IM62 & 14 & OD+IM & 2 & 90 & 0 & 90 & 0.0000 & 18.5862 & SIG \\
\hline IM62 & 0 & OD+IM & 3 & 3 & 7 & 10 & 0.7000 & 31.9987 & NS \\
\hline IM62 & 12 & OD+IM & 4 & 15 & 8 & 23 & 0.3478 & 29.3106 & NS \\
\hline IM62 & 0 & OD+IM & 5 & 117 & 15 & 132 & 0.1136 & 21.2291 & SIG \\
\hline IM62 & 0 & OD+IM & 6 & 62 & 9 & 71 & 0.1268 & 25.6564 & SIG \\
\hline IM62 & 0 & OD+IM & 7 & 48 & 62 & 110 & 0.5636 & 22.2014 & NS \\
\hline IM62 & 13 & OD+IM & 8 & 28 & 15 & 43 & 0.3488 & 24.1408 & NS \\
\hline IM62 & 6 & OD+IM & 9 & 28 & 25 & 53 & 0.4717 & 23.7778 & NS \\
\hline IM62 & 12 & OD+IM & 10 & 39 & 47 & 86 & 0.5465 & 24.0505 & NS \\
\hline IM62 & 5 & OD+IM & 11 & 34 & 46 & 80 & 0.5750 & 25.1875 & NS \\
\hline IM62 & 14 & OD+IM & 12 & 18 & 53 & 71 & 0.7465 & 21.0091 & SIG \\
\hline IM62 & 13 & OD+IM & 13 & 38 & 23 & 61 & 0.3770 & 26.2518 & NS \\
\hline
\end{tabular}




\begin{tabular}{|c|c|c|c|c|c|c|c|c|c|}
\hline IM62 & 13 & $O D+I M$ & 14 & 7 & 37 & 44 & 0.8409 & 24.7432 & SIG \\
\hline IM62 & 2 & $O D+I M$ & 15 & 14 & 23 & 37 & 0.6216 & 24.0467 & NS \\
\hline IM62 & 0 & $O D+I M$ & 16 & 11 & 7 & 18 & 0.3889 & 20.1029 & NS \\
\hline IM62 & 3 & $O D+I M$ & 17 & 6 & 10 & 16 & 0.6250 & 29.2899 & NS \\
\hline IM62 & 0 & $O D+I M$ & 18 & 24 & 6 & 30 & 0.2000 & 24.5210 & NS \\
\hline IM62 & 7 & $O D+I M$ & 19 & 47 & 14 & 61 & 0.2295 & 23.1699 & SIG \\
\hline IM62 & 15 & $O D+I M$ & 20 & 26 & 11 & 37 & 0.2973 & 22.3076 & NS \\
\hline IM62 & 6 & $O D+I M$ & 21 & 41 & 23 & 64 & 0.3594 & 25.3321 & NS \\
\hline IM62 & 6 & $O D+I M$ & 22 & 6 & 0 & 6 & 0.0000 & 25.4753 & NS \\
\hline IM62 & 9 & $O D+I M$ & 23 & 112 & 8 & 120 & 0.0667 & 23.5290 & SIG \\
\hline IM62 & 8 & $O D+I M$ & 24 & 11 & 12 & 23 & 0.5217 & 23.7891 & NS \\
\hline IM62 & 4 & $O D+I M$ & 25 & 5 & 25 & 30 & 0.8333 & 27.2043 & NS \\
\hline IM62 & 0 & $O D+I M$ & 26 & 44 & 11 & 55 & 0.2000 & 24.6987 & SIG \\
\hline IM62 & 0 & $O D+I M$ & 27 & 92 & 10 & 102 & 0.0980 & 25.9432 & SIG \\
\hline IM62 & 0 & $O D+I M$ & 28 & 48 & 20 & 68 & 0.2941 & 22.2567 & NS \\
\hline IM62 & 0 & $O D+I M$ & 29 & 38 & 19 & 57 & 0.3333 & 29.3798 & NS \\
\hline IM62 & 0 & $O D+I M$ & 30 & 41 & 36 & 77 & 0.4675 & 26.0528 & NS \\
\hline HWY15D & 6 & IM62+HWY & 1 & 182 & 157 & 339 & 0.4631 & 13.7714 & NS \\
\hline HWY15D & 4 & IM62+HWY & 2 & 42 & 96 & 138 & 0.6957 & 16.8653 & SIG \\
\hline HWY15D & 6 & IM62+HWY & 3 & 91 & 54 & 145 & 0.3724 & 17.2701 & NS \\
\hline HWY15D & 4 & IM62+HWY & 4 & 139 & 144 & 283 & 0.5088 & 15.3169 & NS \\
\hline HWY15D & 4 & IM62+HWY & 5 & 84 & 160 & 244 & 0.6557 & 15.4467 & SIG \\
\hline HWY15D & 6 & IM62+HWY & 6 & 58 & 61 & 119 & 0.5126 & 17.5574 & NS \\
\hline
\end{tabular}




\begin{tabular}{|c|c|c|c|c|c|c|c|c|c|}
\hline HWY15D & 6 & IM62+HWY & 7 & 65 & 99 & 164 & 0.6037 & 15.2325 & NS \\
\hline HWY15D & 6 & IM62+HWY & 8 & 72 & 61 & 133 & 0.4586 & 16.7600 & NS \\
\hline HWY15D & 6 & IM62+HWY & 9 & 101 & 110 & 211 & 0.5213 & 16.2864 & NS \\
\hline HWY15D & 4 & IM62+HWY & 10 & 63 & 134 & 197 & 0.6802 & 17.3873 & SIG \\
\hline HWY15D & 4 & IM62+HWY & 11 & 44 & 122 & 166 & 0.7349 & 17.8447 & SIG \\
\hline HWY15D & 4 & IM62+HWY & 12 & 30 & 79 & 109 & 0.7248 & 18.8440 & SIG \\
\hline HWY15D & 6 & IM62+HWY & 13 & 22 & 23 & 45 & 0.5111 & 15.9900 & NS \\
\hline HWY15D & 6 & IM62+HWY & 14 & 141 & 105 & 246 & 0.4268 & 14.9731 & NS \\
\hline HWY15D & 6 & IM62+HWY & 15 & 58 & 36 & 94 & 0.3830 & 16.2463 & NS \\
\hline HWY15D & 7 & IM62+HWY & 16 & 149 & 94 & 243 & 0.3868 & 17.2735 & NS \\
\hline HWY15D & 5 & IM62+HWY & 17 & 96 & 135 & 231 & 0.5844 & 13.7065 & NS \\
\hline HWY15D & 5 & IM62+HWY & 18 & 61 & 108 & 169 & 0.6391 & 14.1027 & NS \\
\hline HWY15D & 7 & IM62+HWY & 19 & 80 & 62 & 142 & 0.4366 & 17.4737 & NS \\
\hline HWY15D & 7 & IM62+HWY & 20 & 46 & 32 & 78 & 0.4103 & 16.4966 & NS \\
\hline HWY15D & 7 & IM62+HWY & 21 & 124 & 72 & 196 & 0.3673 & 16.3268 & NS \\
\hline HWY15D & 7 & IM62+HWY & 22 & 15 & 57 & 72 & 0.7917 & 16.2255 & SIG \\
\hline HWY15D & 4 & IM62+HWY & 23 & 82 & 163 & 245 & 0.6653 & 15.9680 & SIG \\
\hline HWY15D & 6 & IM62+HWY & 24 & 132 & 52 & 184 & 0.2826 & 13.3957 & SIG \\
\hline HWY15D & 6 & IM62+HWY & 25 & 214 & 137 & 351 & 0.3903 & 13.7087 & SIG \\
\hline HWY15D & 4 & IM62+HWY & 26 & 37 & 141 & 178 & 0.7921 & 18.2464 & SIG \\
\hline HWY15D & 4 & IM62+HWY & 27 & 10 & 12 & 22 & 0.5455 & 21.0723 & NS \\
\hline HWY15D & 6 & IM62+HWY & 28 & 36 & 43 & 79 & 0.5443 & 13.8636 & NS \\
\hline HWY15D & 4 & IM62+HWY & 29 & 49 & 40 & 89 & 0.4494 & 16.5796 & NS \\
\hline
\end{tabular}




\begin{tabular}{|c|c|c|c|c|c|c|c|c|c|}
\hline HWY15D & 6 & IM62+HWY & 30 & 99 & 98 & 197 & 0.4975 & 13.4846 & NS \\
\hline HWY15D & 6 & OD+HWY15 & 1 & 166 & 65 & 231 & 0.2814 & 14.7041 & SIG \\
\hline HWY15D & 6 & OD+HWY15 & 2 & 229 & 145 & 374 & 0.3877 & 14.6194 & SIG \\
\hline HWY15D & 6 & OD+HWY15 & 3 & 276 & 152 & 428 & 0.3551 & NA & SIG \\
\hline HWY15D & 6 & OD+HWY15 & 4 & 206 & 110 & 316 & 0.3481 & 14.5547 & SIG \\
\hline HWY15D & 4 & OD+HWY15 & 5 & 30 & 90 & 120 & 0.7500 & 16.4631 & SIG \\
\hline HWY15D & 4 & OD+HWY15 & 6 & 92 & 88 & 180 & 0.4889 & 17.2475 & NS \\
\hline HWY15D & 6 & OD+HWY15 & 7 & 48 & 32 & 80 & 0.4000 & 17.5165 & NS \\
\hline HWY15D & 6 & OD+HWY15 & 8 & 183 & 78 & 261 & 0.2989 & 15.0614 & SIG \\
\hline HWY15D & 4 & OD+HWY15 & 9 & 19 & 19 & 38 & 0.5000 & 20.1781 & NS \\
\hline HWY15D & 4 & OD+HWY15 & 10 & 217 & 161 & 378 & 0.4259 & 14.3388 & NS \\
\hline HWY15D & 4 & OD+HWY15 & 11 & 231 & 162 & 393 & 0.4122 & 13.8283 & NS \\
\hline HWY15D & 4 & OD+HWY15 & 12 & 121 & 71 & 192 & 0.3698 & 15.8368 & NS \\
\hline HWY15D & 6 & OD+HWY15 & 13 & 64 & 57 & 121 & 0.4711 & 14.9187 & NS \\
\hline HWY15D & 6 & OD+HWY15 & 14 & 29 & 32 & 61 & 0.5246 & 15.5215 & NS \\
\hline HWY15D & 6 & OD+HWY15 & 15 & 37 & 12 & 49 & 0.2449 & 17.8154 & NS \\
\hline HWY15D & 6 & OD+HWY15 & 16 & 26 & 57 & 83 & 0.6867 & 14.6550 & NS \\
\hline HWY15D & 4 & OD+HWY15 & 17 & 265 & 96 & 361 & 0.2659 & 15.5190 & SIG \\
\hline HWY15D & 4 & OD+HWY15 & 18 & 313 & 132 & 445 & 0.2966 & 14.8546 & SIG \\
\hline HWY15D & 6 & OD+HWY15 & 19 & 129 & 107 & 236 & 0.4534 & 16.2029 & NS \\
\hline HWY15D & 5 & OD+HWY15 & 20 & 10 & 39 & 49 & 0.7959 & 17.1143 & SIG \\
\hline HWY15D & 5 & OD+HWY15 & 21 & 126 & 166 & 292 & 0.5685 & 14.4543 & NS \\
\hline HWY15D & 5 & OD+HWY15 & 22 & 64 & 134 & 198 & 0.6768 & 13.1848 & SIG \\
\hline
\end{tabular}




\begin{tabular}{|c|c|c|c|c|c|c|c|c|c|}
\hline HWY15D & 6 & OD+HWY15 & 23 & 126 & 96 & 222 & 0.4324 & 15.9587 & NS \\
\hline HWY15D & 6 & OD+HWY15 & 24 & 88 & 72 & 160 & 0.4500 & 19.0036 & NS \\
\hline HWY15D & 4 & OD+HWY15 & 25 & 53 & 72 & 125 & 0.5760 & 15.0604 & NS \\
\hline OD11 & 3 & HWY15+OD & 1 & 64 & 104 & 168 & 0.6190 & 14.1142 & NS \\
\hline OD11 & 3 & HWY15+OD & 2 & 6 & 32 & 38 & 0.8421 & 15.3353 & SIG \\
\hline OD11 & 3 & HWY15+OD & 3 & 16 & 110 & 126 & 0.8730 & 15.9940 & SIG \\
\hline OD11 & 5 & HWY15+OD & 4 & 12 & 95 & 107 & 0.8879 & 15.9141 & SIG \\
\hline OD11 & 5 & HWY15+OD & 5 & 6 & 121 & 127 & 0.9528 & 14.3608 & SIG \\
\hline OD11 & 5 & HWY15+OD & 6 & 8 & 35 & 43 & 0.8140 & 14.8058 & SIG \\
\hline OD11 & 5 & HWY15+OD & 7 & 8 & 97 & 105 & 0.9238 & 14.8111 & SIG \\
\hline OD11 & 5 & HWY15+OD & 8 & 12 & 154 & 166 & 0.9277 & 15.4242 & SIG \\
\hline OD11 & 5 & HWY15+OD & 9 & 4 & 67 & 71 & 0.9437 & 15.9485 & SIG \\
\hline OD11 & 3 & HWY15+OD & 10 & 23 & 137 & 160 & 0.8563 & 17.6589 & SIG \\
\hline OD11 & 3 & HWY15+OD & 11 & 13 & 36 & 49 & 0.7347 & 19.9525 & NS \\
\hline OD11 & 3 & HWY15+OD & 12 & 2 & 19 & 21 & 0.9048 & 14.7240 & SIG \\
\hline OD11 & 5 & HWY15+OD & 13 & 20 & 74 & 94 & 0.7872 & 15.2884 & SIG \\
\hline OD11 & 5 & HWY15+OD & 14 & 8 & 61 & 69 & 0.8841 & 17.9506 & SIG \\
\hline OD11 & 3 & HWY15+OD & 15 & 7 & 20 & 27 & 0.7407 & 15.7819 & NS \\
\hline OD11 & 5 & HWY15+OD & 16 & 7 & 53 & 60 & 0.8833 & 15.3839 & SIG \\
\hline OD11 & 3 & HWY15+OD & 17 & 10 & 74 & 84 & 0.8810 & 17.4214 & SIG \\
\hline OD11 & 5 & HWY15+OD & 18 & 2 & 54 & 56 & 0.9643 & 18.0635 & SIG \\
\hline OD11 & 5 & HWY15+OD & 19 & 2 & 51 & 53 & 0.9623 & 15.7985 & SIG \\
\hline OD11 & 5 & HWY15+OD & 20 & 6 & 26 & 32 & 0.8125 & 18.4395 & NS \\
\hline
\end{tabular}




\begin{tabular}{|c|c|c|c|c|c|c|c|c|c|}
\hline OD11 & 3 & HWY15+OD & 21 & 4 & 11 & 36 & 0.3056 & 19.8088 & NS \\
\hline OD11 & 3 & HWY15+OD & 22 & 0 & 11 & 11 & 1.0000 & & NS \\
\hline IM62 & 0 & IM62+HWY & 1 & 67 & 108 & 175 & 0.6171 & 25.0784 & NS \\
\hline IM62 & 7 & IM62+HWY & 2 & 34 & 26 & 60 & 0.4333 & 15.3029 & NS \\
\hline IM62 & 9 & IM62+HWY & 3 & 64 & 41 & 105 & 0.3905 & 23.5853 & NS \\
\hline IM62 & 15 & IM62+HWY & 4 & 117 & 73 & 190 & 0.3842 & 22.9275 & NS \\
\hline IM62 & 8 & IM62+HWY & 5 & 42 & 51 & 93 & 0.5484 & 21.2626 & NS \\
\hline IM62 & 5 & IM62+HWY & 6 & 5 & 11 & 16 & 0.6875 & 23.9093 & NS \\
\hline IM62 & 12 & IM62+HWY & 7 & 56 & 35 & 91 & 0.3846 & 23.5435 & NS \\
\hline IM62 & 9 & IM62+HWY & 8 & 7 & 18 & 25 & 0.7200 & 28.8460 & NS \\
\hline IM62 & 15 & IM62+HWY & 9 & 6 & 19 & 25 & 0.7600 & 27.4792 & NS \\
\hline IM62 & 5 & IM62+HWY & 10 & 33 & 35 & 68 & 0.5147 & 28.8596 & NS \\
\hline IM62 & 5 & IM62+HWY & 11 & 43 & 121 & 164 & 0.7378 & 28.8578 & SIG \\
\hline IM62 & 12 & IM62+HWY & 12 & 67 & 157 & 224 & 0.7009 & 21.8156 & SIG \\
\hline IM62 & 11 & IM62+HWY & 13 & 36 & 34 & 70 & 0.4857 & 25.0363 & NS \\
\hline IM62 & 12 & IM62+HWY & 14 & 41 & 61 & 102 & 0.5980 & 30.0482 & NS \\
\hline IM62 & 0 & IM62+HWY & 15 & 8 & 22 & 30 & 0.7333 & 22.3832 & NS \\
\hline IM62 & 0 & IM62+HWY & 16 & 27 & 79 & 106 & 0.7453 & 26.9391 & SIG \\
\hline IM62 & 0 & IM62+HWY & 17 & 18 & 17 & 35 & 0.4857 & 34.5770 & NS \\
\hline IM62 & 0 & IM62+HWY & 18 & 34 & 67 & 101 & 0.6634 & 32.6350 & NS \\
\hline IM62 & 0 & IM62+HWY & 19 & 42 & 40 & 82 & 0.4878 & 28.8821 & NS \\
\hline IM62 & 5 & IM62+HWY & 20 & 54 & 108 & 162 & 0.6667 & 23.8263 & SIG \\
\hline IM62 & 5 & IM62+HWY & 21 & 22 & 21 & 43 & 0.4884 & 28.3003 & NS \\
\hline
\end{tabular}




\begin{tabular}{|c|c|c|c|c|c|c|c|c|c|}
\hline IM62 & 5 & IM62+HWY & 22 & 19 & 53 & 72 & 0.7361 & 29.2312 & SIG \\
\hline IM62 & 4 & IM62+HWY & 23 & 30 & 86 & 116 & 0.7414 & 30.3648 & SIG \\
\hline IM62 & 2 & IM62+HWY & 24 & 28 & 22 & 50 & 0.4400 & 28.9807 & NS \\
\hline IM62 & 13 & IM62+HWY & 25 & 42 & 43 & 85 & 0.5059 & 30.1018 & NS \\
\hline IM62 & 13 & IM62+HWY & 26 & 43 & 47 & 90 & 0.5222 & 32.1721 & NS \\
\hline IM62 & 9 & IM62+HWY & 27 & 7 & 29 & 36 & 0.8056 & 24.5183 & NS \\
\hline IM62 & 0 & IM62+HWY & 28 & 77 & 67 & 144 & 0.4653 & 22.7292 & NS \\
\hline IM62 & 12 & IM62+HWY & 29 & 27 & 34 & 61 & 0.5574 & 21.2397 & NS \\
\hline IM62 & 12 & IM62+HWY & 30 & 48 & 53 & 101 & 0.5248 & 24.7898 & NS \\
\hline OD11 & 5 & IM62+OD & 1 & 1 & 27 & 28 & 0.9643 & & SIG \\
\hline OD11 & 2 & IM62+OD & 2 & 8 & 84 & 92 & 0.9130 & & SIG \\
\hline OD11 & 3 & IM62+OD & 3 & 13 & 87 & 100 & 0.8700 & & NA \\
\hline IM62 & 0 & IM62 & 1 & 164 & 8 & 172 & 0.0465 & 21.5154 & NA \\
\hline IM62 & 7 & |IM62 & 2 & 69 & 10 & 79 & 0.1266 & 26.9359 & NA \\
\hline IM62 & 16 & IM62 & 3 & 154 & 8 & 162 & 0.0494 & 22.1432 & NA \\
\hline IM62 & 0 & IM62 & 4 & 115 & 5 & 120 & 0.0417 & 25.9444 & NA \\
\hline IM62 & 0 & IM62 & 5 & 24 & 9 & 33 & 0.2727 & 23.4533 & NA \\
\hline IM62 & 7 & |IM62 & 6 & 136 & 5 & 141 & 0.0355 & 17.7310 & NA \\
\hline IM62 & 16 & IM62 & 7 & 140 & 4 & 144 & 0.0278 & 22.7858 & NA \\
\hline IM62 & 11 & IM62 & 8 & 120 & 3 & 123 & 0.0244 & 26.9818 & NA \\
\hline IM62 & 10 & IM62 & 9 & 101 & 3 & 104 & 0.0288 & 26.8373 & NA \\
\hline IM62 & 13 & IM62 & 10 & 58 & 2 & 60 & 0.0333 & 32.8099 & NA \\
\hline IM62 & 13 & |IM62 & 11 & 51 & 5 & 56 & 0.0893 & 35.3827 & NA \\
\hline
\end{tabular}




\begin{tabular}{|c|c|c|c|c|c|c|c|c|c|}
\hline IM62 & 11 & |IM62 & 12 & 98 & 3 & 101 & 0.0297 & 22.9827 & NA \\
\hline IM62 & 6 & IM62 & 13 & 96 & 4 & 100 & 0.0400 & 24.3869 & NA \\
\hline IM62 & 6 & |IM62 & 14 & 50 & 1 & 51 & 0.0196 & 27.9854 & NA \\
\hline IM62 & 6 & IM62 & 15 & 109 & 0 & 109 & 0.0000 & 24.8258 & NA \\
\hline IM62 & 6 & |IM62 & 16 & 55 & 3 & 58 & 0.0517 & 27.3090 & NA \\
\hline IM62 & 6 & |IM62 & 17 & 83 & 0 & 83 & 0.0000 & 25.7117 & NA \\
\hline IM62 & 4 & |IM62 & 18 & 44 & 1 & 45 & 0.0222 & 27.6953 & NA \\
\hline IM62 & 6 & |IM62 & 19 & 90 & 3 & 93 & 0.0323 & 19.6464 & NA \\
\hline IM62 & 13 & IM62 & 20 & 25 & 2 & 27 & 0.0741 & 28.5040 & NA \\
\hline IM62 & 16 & |IM62 & 21 & 112 & 14 & 126 & 0.1111 & 21.8118 & NA \\
\hline IM62 & 7 & |IM62 & 22 & 59 & 4 & 63 & 0.0635 & 20.1915 & NA \\
\hline IM62 & 10 & |IM62 & 23 & 74 & 2 & 76 & 0.0263 & 27.7943 & NA \\
\hline IM62 & 10 & |IM62 & 24 & 95 & 1 & 96 & 0.0104 & 22.5340 & NA \\
\hline IM62 & 9 & IM62 & 25 & 92 & 0 & 92 & 0.0000 & 19.2019 & NA \\
\hline IM62 & 9 & IM62 & 26 & 146 & 4 & 150 & 0.0267 & 25.5663 & NA \\
\hline IM62 & 9 & IM62 & 27 & 84 & 5 & 89 & 0.0562 & 29.6586 & NA \\
\hline IM62 & 16 & IM62 & 28 & 157 & 2 & 159 & 0.0126 & 25.3686 & NA \\
\hline IM62 & 16 & |IM62 & 29 & 26 & 6 & 32 & 0.1875 & 26.4208 & NA \\
\hline IM62 & 16 & |IM62 & 30 & 81 & 4 & 85 & 0.0471 & 22.0754 & NA \\
\hline IM62 & 11 & IM62 & 31 & 131 & 8 & 139 & 0.0576 & 20.5657 & NA \\
\hline HWY15D & 6 & HWY15 & 1 & 152 & 22 & 174 & 0.1264 & 13.8366 & NA \\
\hline HWY15D & 6 & HWY15 & 2 & 214 & 17 & 231 & 0.0736 & 13.6000 & NA \\
\hline HWY15D & 4 & HWY15 & 3 & 15 & 3 & 18 & 0.1667 & 20.6085 & NA \\
\hline
\end{tabular}




\begin{tabular}{|c|c|c|c|c|c|c|c|c|c|}
\hline HWY15D & 5 & HWY15 & 4 & 268 & 29 & 297 & 0.0976 & 15.1823 & NA \\
\hline HWY15D & 6 & HWY15 & 5 & 50 & 9 & 59 & 0.1525 & 18.2932 & NA \\
\hline HWY15D & 6 & HWY15 & 6 & 42 & 8 & 50 & 0.1600 & 21.6989 & NA \\
\hline HWY15D & 4 & HWY15 & 7 & 279 & 27 & 306 & 0.0882 & 16.3628 & NA \\
\hline HWY15D & 4 & HWY15 & 8 & 186 & 24 & 210 & 0.1143 & 15.4090 & NA \\
\hline HWY15D & 6 & HWY15 & 9 & 218 & 28 & 246 & 0.1138 & 15.2564 & NA \\
\hline HWY15D & 6 & HWY15 & 10 & 180 & 21 & 201 & 0.1045 & 15.5260 & NA \\
\hline HWY15D & 6 & HWY15 & 11 & 174 & 34 & 208 & 0.1635 & 13.7842 & NA \\
\hline HWY15D & 7 & HWY15 & 12 & 153 & 18 & 171 & 0.1053 & 16.4726 & NA \\
\hline HWY15D & 4 & HWY15 & 13 & 155 & 13 & 168 & 0.0774 & 17.1155 & NA \\
\hline HWY15D & 4 & HWY15 & 14 & 208 & 21 & 229 & 0.0917 & 13.8453 & NA \\
\hline HWY15D & 4 & HWY15 & 15 & 366 & 12 & 378 & 0.0317 & 14.6420 & NA \\
\hline HWY15D & 4 & HWY15 & 16 & 261 & 32 & 293 & 0.1092 & 14.0407 & NA \\
\hline HWY15D & 6 & HWY15 & 17 & 87 & 18 & 105 & 0.1714 & 14.8045 & NA \\
\hline HWY15D & 4 & HWY15 & 18 & 349 & 27 & 376 & 0.0718 & 14.7766 & NA \\
\hline HWY15D & 4 & HWY15 & 19 & 274 & 15 & 289 & 0.0519 & 16.2413 & NA \\
\hline HWY15D & 6 & HWY15 & 20 & 222 & 34 & 256 & 0.1328 & 16.8549 & NA \\
\hline HWY15D & 6 & HWY15 & 21 & 242 & 24 & 266 & 0.0902 & 15.4280 & NA \\
\hline HWY15D & 6 & HWY15 & 22 & 49 & 9 & 58 & 0.1552 & 21.0781 & NA \\
\hline HWY15D & 6 & HWY15 & 23 & 30 & 16 & 46 & 0.3478 & 20.7791 & NA \\
\hline HWY15D & 6 & HWY15 & 24 & 322 & 9 & 331 & 0.0272 & 14.9536 & NA \\
\hline OD11 & 3 & OD11 & 1 & 87 & 34 & 121 & 0.2810 & 11.4002 & NA \\
\hline OD11 & 3 & OD11 & 2 & 104 & 32 & 136 & 0.2353 & 12.1900 & NA \\
\hline
\end{tabular}




\begin{tabular}{|c|c|c|c|c|c|c|c|c|c|}
\hline OD11 & 5 & OD11 & 3 & 113 & 54 & 167 & 0.3234 & 16.5155 & NA \\
\hline OD11 & 5 & OD11 & 4 & 137 & 44 & 181 & 0.2431 & 16.2901 & NA \\
\hline OD11 & 5 & OD11 & 5 & 143 & 66 & 209 & 0.3158 & 15.7383 & NA \\
\hline OD11 & 5 & OD11 & 6 & 16 & 8 & 24 & 0.3333 & 13.2572 & NA \\
\hline OD11 & 3 & OD11 & 7 & 162 & 73 & 235 & 0.3106 & 13.5372 & NA \\
\hline OD11 & 3 & OD11 & 8 & 15 & 5 & 20 & 0.2500 & 15.1527 & NA \\
\hline OD11 & 3 & OD11 & 9 & 68 & 13 & 81 & 0.1605 & 13.1667 & NA \\
\hline OD11 & 3 & OD11 & 10 & 50 & 16 & 66 & 0.2424 & 11.1004 & NA \\
\hline OD11 & 3 & OD11 & 11 & 89 & 14 & 103 & 0.1359 & 12.2546 & NA \\
\hline OD11 & 3 & OD11 & 12 & 88 & 18 & 106 & 0.1698 & 15.5921 & NA \\
\hline OD11 & 5 & OD11 & 13 & 6 & 4 & 10 & 0.4000 & 14.5205 & NA \\
\hline OD11 & 5 & OD11 & 14 & 78 & 43 & 121 & 0.3554 & 13.6518 & NA \\
\hline OD11 & 2 & OD11 & 15 & 64 & 54 & 118 & 0.4576 & 15.6383 & NA \\
\hline OD11 & 2 & OD11 & 16 & 76 & 34 & 110 & 0.3091 & 12.7179 & NA \\
\hline OD11 & 2 & OD11 & 17 & 75 & 35 & 110 & 0.3182 & 13.2970 & NA \\
\hline OD11 & 3 & OD11 & 18 & 104 & 52 & 156 & 0.3333 & 14.4804 & NA \\
\hline OD11 & 3 & OD11 & 19 & 97 & 65 & 162 & 0.4012 & 12.8145 & NA \\
\hline OD11 & 3 & OD11 & 20 & 35 & 21 & 56 & 0.3750 & 11.5924 & NA \\
\hline
\end{tabular}

